\title{
Spontaneous Subclavian Artery Transection after Sneezing
}

\author{
Hapşırma Sonrası Gelişen Spontan Subklavyen Arter Transeksiyonu
}

\author{
Seçkin Bahar Sezgin', Gökhan Aksel', Hande Akbal', Özlem Güneysel², Şebnem Eren Çevik' \\ ${ }^{1}$ Clinic of Emergency Medicine, Ümraniye Training and Research Hospital,İstanbul, Turkey \\ ${ }^{2}$ Clinic of Emergency Medicine, Dr. Lütfi Kırdar Kartal Training and Research Hospital İstanbul, Turkey
}

\section{ABSTRACT}

Introduction: Spontaneous subclavian artery injuries are extremely rare vascular emergencies. We aimed to present a case with subclavian artery transection after sneezing.

Case Report: An 18-year-old male presented to the emergency department with the complaint of right shoulder pain after sneezing. His vital signs and physical examination were all normal. On the chest radiography, the mediastinal width was $7 \mathrm{~cm}$. He was discharged. He presented to the emergency department after 5 hours from discharge with complaints of chest pain and dyspnea. He was hypotensive and tachycardic. Brachial and radial pulses were not palpable. A massive hemothorax was detected. Tube thoracostomy was performed, and his hemodynamic parameters deteriorated rapidly. Urgent thoracotomy was performed, and cardiac arrest occurred during the hemorrhage control. In the postmortem exploration, a complete subclavian artery transection was confirmed at the outlet of the arcus aorta.

Conclusion: Sneezing is a minor trauma that precipitates spontaneous artery dissection. It was known that a mediastinal width of over $6 \mathrm{~cm}$ is associated with increased mortality. An advanced radiological assessment will be useful for patients who present to the emergency department with complaints of chest, back, shoulder, or arm pain after a sudden movement and have a mediastinal width of over $6 \mathrm{~cm}$.

Keywords: Sneezing, subclavian artery transection, emergency medicine

Received: 24.09.2014 Accepted: 10.10.2014

\section{ÖZET}

Giriş: Spontan subklavyen arter yaralanmaları nadir rastlanır. Hapşırma sonrası spontan subklavyen arter transeksiyonunu gelişen bir olguyu sunmayı amaçladık.

Olgu Sunumu: 18 yaşında erkek hasta acil servise hapşırma sonrası sağ omuz ağrısı şikayeti ile başvurdu. Hastanın vital bulguları ve fizik muayenesi normaldi. Akciğer grafisinde mediasten genişliği $7 \mathrm{~cm}$ idi. Hasta taburcu edildi. Hasta taburculuğundan beş saat sonra acil servise nefes darlığı ve göğüs ağrısı şikayeti ile başvurdu. Hipotansif ve taşikardik olan hastanın sağ brakial ve radial nabızlar palpe edilemedi. Masif hemotoraks tespit edildi. Tüp torakostomi yapıldı, hemodimisinin hızla bozulması üzerine acil torakotomi yapılan hastada kanama kontrolü esnasında kardiyak arrest gelişti. Postmortem yapılan eksplorasyonda sağ subklavyen arterin arcus aorta birleşme noktasından sirküler olarak tam kat yırtılmaya bağlı olarak tamamen ayrıldığı (komplet transeksiyon) görüldü.

Sonuç: Hapşırma, spontan arter diseksiyonunu tetikleyen minör travmalar arasında yer almaktadır. $6 \mathrm{~cm}$ ve üzerindeki mediasten genişliği üç kat artmış mortalite ile ilişkili bulunmuştur. Acil servise özellikle ani hareket sonrası başlayan göğüs, sırt, omuz ve kol ağrısı gibi yakınmalarla başvuran ve akciğer grafisinde $\geq 6$ cm mediastinal genişlik tespit edilen hastalarda ileri görüntüleme yapılmasının bu olgudaki gibi nadir ancak mortalitesi yüksek hastalıkların tanınmasında faydalı olabileceğini düşünmekteyiz.

Anahtar Kelimeler: Hapşırma, subklavyen arter transeksiyonu, acil tıp

Geliş Tarihi: 24.09.2014 Kabul Tarihi: 10.10.2014 


\section{Giriş}

Aort yaralanmaları genellikle deselerasyon ve horizontal kuvvetlerin uygulanması ile meydana gelir. Çoğunlukla yüksek enerjili motorlu taşıt kazaları sonrası gelişir. Künt toraks travmalarında genellikle aortun istmus olarak adlandırılan; sol subclavian arterin distali ile üçüncü interkostal arterin proksimali arasında kalan bölgesinde yırtılma oluşur (1). Subklavyen arter yaralanmaları da çoğunlukla yüksek enerjili künt travmaya bağlı veya iatrojenik olarak görülürken, spontan subklavyen arter rüptürü çok daha nadir rastlanan bir klinik tablodur (2, 3). Bu yazıda çok nadir görülen travmatik ya da iyatrojenik olmayan, hapşırma ile tetiklenen spontan subklavyen arter transeksiyonu olan bir olguyu tartışmayı amaçladık.

\section{Olgu Sunumu}

18 yaşında erkek hasta sağ omuzda ağrı ve şüpheli mediastinal genişlik nedeniyle acil servisimize dış merkezden sevk edildi. Hastanın ağrısının hapşırma sonrası akut başlangıçlı olduğu, dış merkezde yapılan analjezik sonrası şikayetinin gerilediği öğrenildi. Hastanın özgeçmişinde konjenital pilor stenozu, inmemiş testis ve aşiloplasti operasyon öyküsü mevcuttu. Başvuru esnasında asemptomatik olan hastanın fizik bakısında kan basıncı sağ kol: 120/68 mmHg, sol kol: 114/70 mmHg, nabız: 85/dk, O saturasyonu \%98 olarak ölçüldü. Diğer sistem muayenelerinde özellik yoktu. Arter kan gazı değerleri normal, ayakta çekilen akciğer grafisinde mediasten $7 \mathrm{~cm}$ olarak ölçülmüş olup diğer yapılar normal olarak izlendi (Resim 1a). Aktif yakınması olmayan, fizik bakısı normal olan hasta taburcu edildi. Yaklaşık 5 saat sonra hasta göğüs ağrısı ve nefes darlığı şikayeti ile tekrar başvurdu. Kan basıncl: 68/42mmHg (sağ kol), 76/45 mmHg (sol kol) nabız: 120/dk, sat $\mathrm{O}_{2}$ : \%98 idi. Fizik bakısında sağ akciğer orta ve alt zonlarda solunum sesleri azalmıştı, sağ kolda uyuşma tarifleyen hastanın sağ brakial ve radial nabzı palpe edilemedi. Elektrokardiyografisi sinus taşikardisi ile uyumluydu, akciğer grafisinde sağda belirgin plevral efüzyon mevcuttu (Resim 1b). Yapılan yatak başı ultrasonografisinde sağ plevral efüzyon tespit edilen hastaya torasentez yapıldı. Torasentezde hemorajik mayi görülmesi üzerine BT anjiografi çekildi.
Sağ hemitoraksı yarıya yakın dolduran hemotoraks izlendi, büyük damarlara ait belirgin bir patoloji gözlenmedi (Resim 2). Yapılan uygun Sıvı ve kan resusitasyonu sonrası vital bulguları stabil olan hastaya göğüs tüpü takıldı. Tüp torakostomi yapılır yapılmaz 1000 cc'den fazla kan gelen ve hızla hemodinamisi bozulan hastaya acil torakotomi yapıldı. Mediastende abondan kanama tespit edildi. Girişim esnasında kardiyak arrest gelişen hastaya yeniden canlandırma işlemi uygulandı, yanıt alınamadı. Postmortem yapılan eksplorasyonda sağ subklavyen arterin arkus aorta birleşme noktasından sirküler olarak tam kat yırtılmaya bağlı olarak tamamen ayrıldığı (komplet transeksiyon) görüldü (Resim 3).

\section{Tartışma}

Künt travmaya bağlı aort transeksiyonu nadir rastlanan bir klinik durumdur ve yapılan çalışmalarda çoğunlukla trafik kazaları sonrası görülmektedir $(1,4)$. Spontan arter diseksiyonunu tetikleyen nedenler arasında yoga, tavan boyama, öksürme, kusma, hapşırma gibi minör travmalar yer almaktadır (5). Bu nedenler arasında yer alan hapşırma ılımlı natürde potansiyel mekanik tetikleyici bir olaydır. Bu olguda da hapşırma sonucunda sağ subklavian arterde komplet transeksiyon meydana gelmiştir. Literatürde subklavyen artere ait spontan rüptür vakaları daha çok nörofibromatozis ve Ehlers-Danlos gibi altta yatan hastalığı olan kişilerde tanımlanmıştır (6-8). Bu hastanın tanı almış herhangi bir kronik hastalığı bulunmamaktadır. Hastanın özgeçmişinde konjenital hipertrofik pilor stenozu, kriptorşidizm ve aşil tendon kontraktürü olması, eşlik eden tanı almamış bir sendromunun ya da ek konjenital anomalilerinin olabileceğini düşündürmektedir.

Hasta ilk başvurusunda semptomu olmaması, normal fizik muayene bulgularının olması ve akciğer grafisinde mediastenin $7 \mathrm{~cm}$ (normalin üst sınırı) ölçülmesi nedeniyle ileri tetkik ve değerlendirme düşünülmeyerek taburcu edilmiştir. Mediastinal genişlik aort diseksiyonu, anevrizması ve mediastinal hematom gibi klinik durumların göstergesi olabilir. Literatürde mediastinal genişlik tanımına dair net bir sınır değer bulunmamaktadır. Bazı çalışmalar mediastinal genişlik

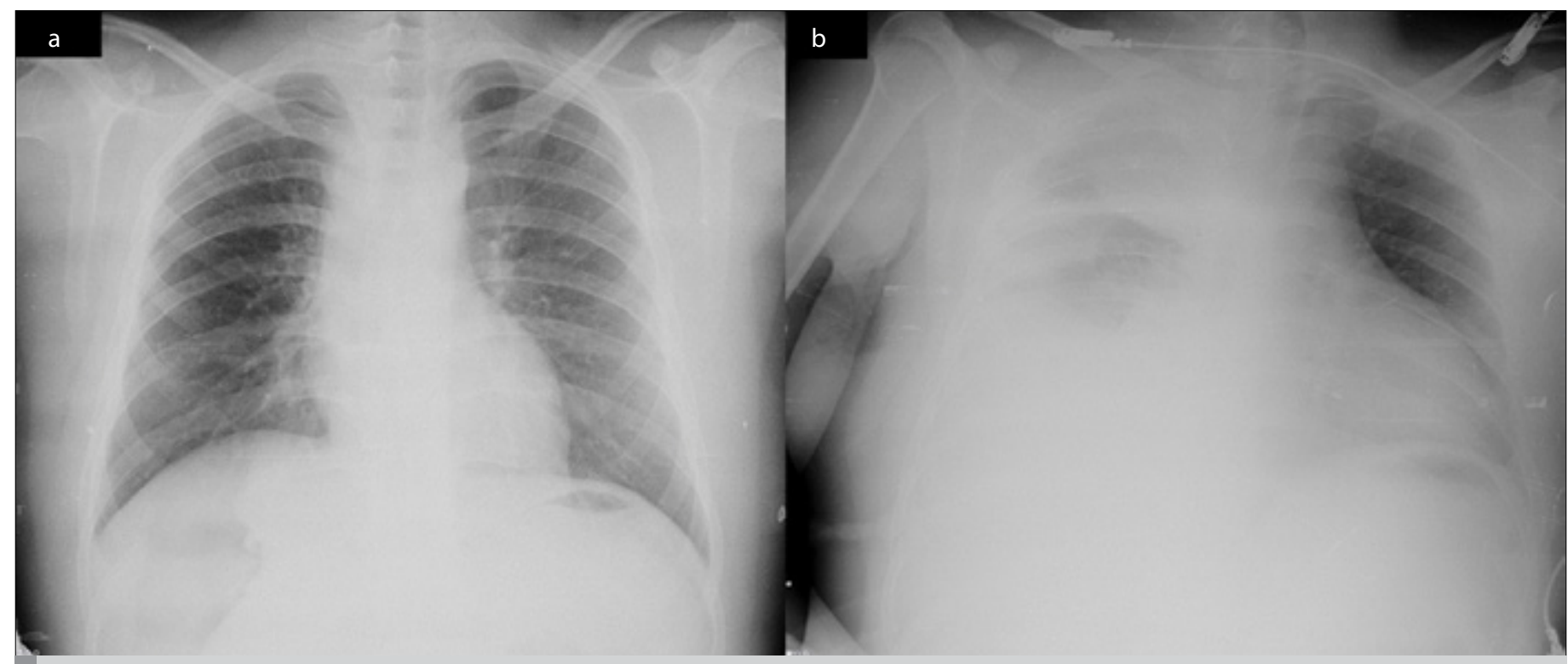

Resim 1. a, b. Hastanın ilk başvurusu esnasında çekilen akciğer grafisi (a), Hastanın ikinci başvurusu esnasında çekilen akciğer grafisi (b) 


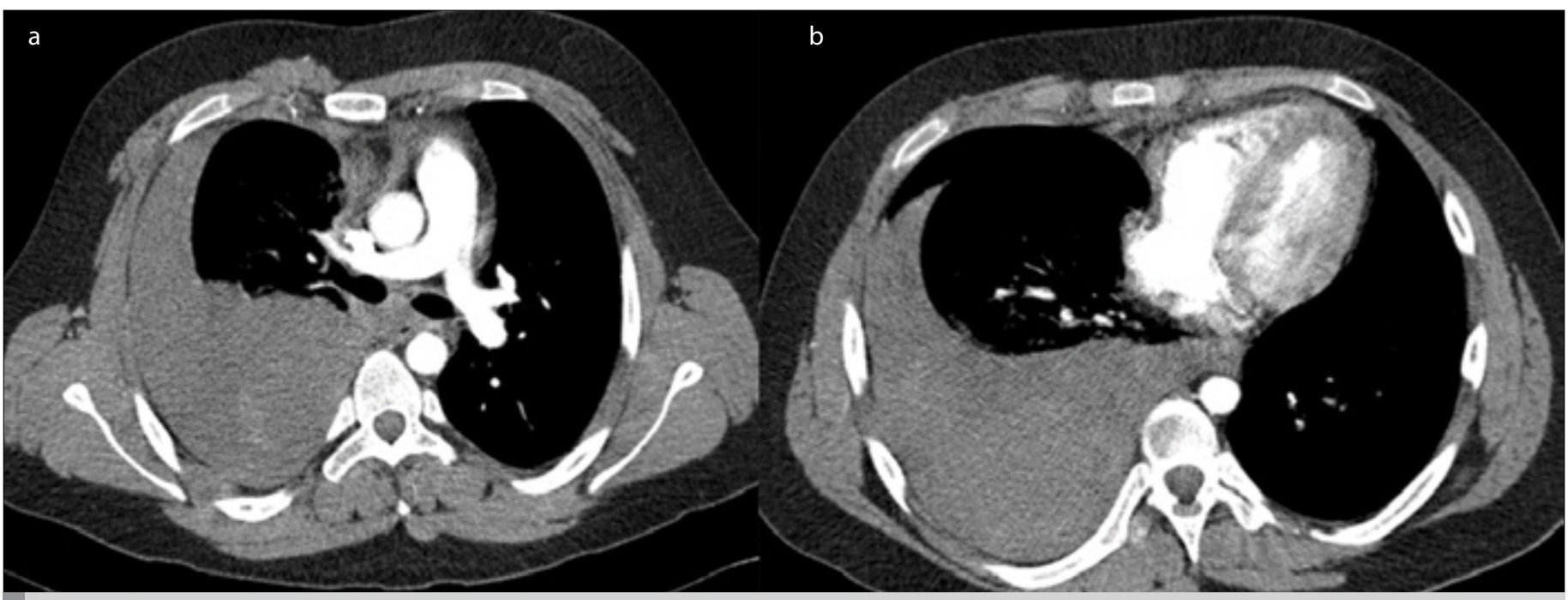

Resim 2. a, b. Hastanın toraks tomografisi görüntüleri

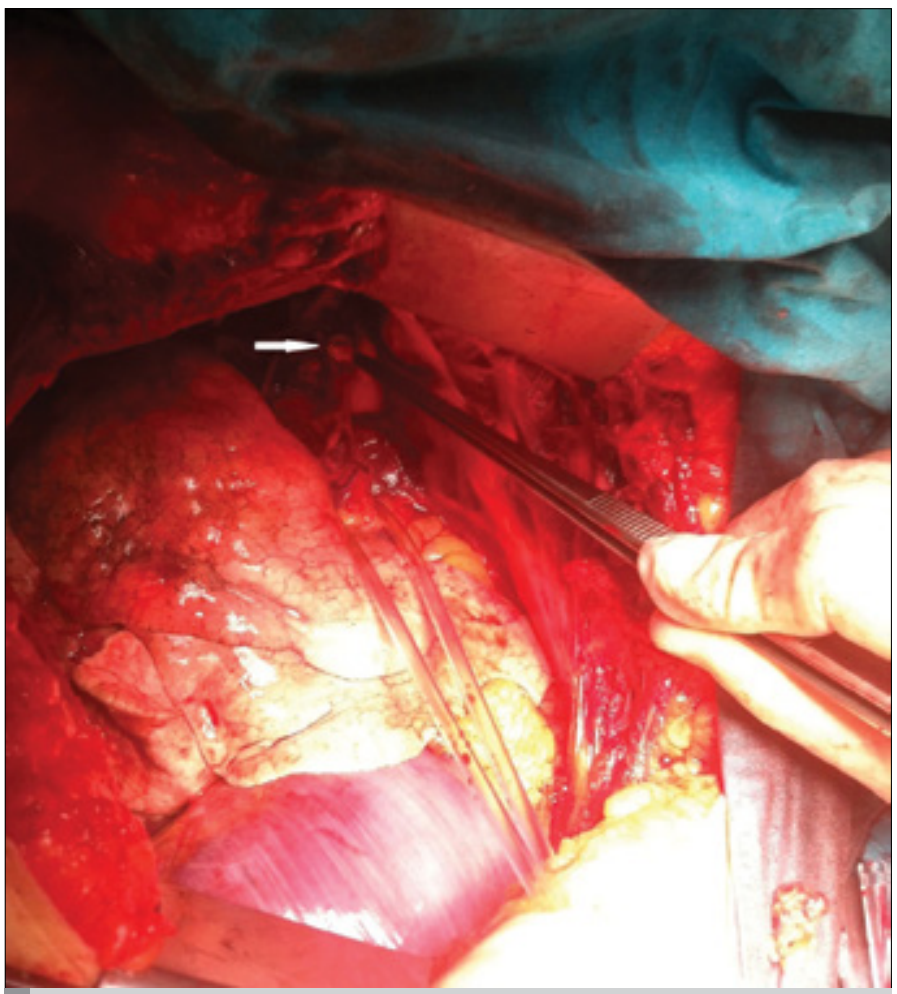

Resim 3. Postmortem eksplorasyonda görülen subklavyen arterde tam kat yırtık

tanımı için sınır değeri 7,3-9,4 cm aralığı olarak vermektedirler (9). Bu hastanın başvuru esnasında asemptomatik olup hemodinamisinin stabil olması acil servis doktorları için yanıltıcı olmuştur. Her ne kadar bu hastada $7 \mathrm{~cm}$ olarak ölçülen mediastinal genişlik bazı çalışmalara göre normal kabul edilebilirse de, Suzuki ve ark. (10) $\geq 6 \mathrm{~cm}$ mediastinal genişliğin yaklaşık 3 kat artmış mortalite ile ilişkili olduğunu bildirmişlerdir. Bu sebeple bu hastadaki mediastinal genişlik için mediasten üst sınırına ait eşik değer daha düşük kabul edilip ilk başvuru esnasında ileri görüntüleme yapılsaydı mediastinal hematom tespit edilmesi mümkün olabilirdi.

\section{Sonuç}

Acil servise özellikle ani hareket sonrası başlayan göğüs, sırt, omuz ve kol ağrısı gibi yakınmalarla başvuran ve akciğer grafisinde $\geq 6 \mathrm{~cm}$ mediastinal genişlik tespit edilen hastalarda ileri görüntüleme yapıması, bu olgudaki gibi nadir ancak mortalitesi yüksek hastalıkların tanınmasında faydalı olabilir

Hasta Onamı: Yazılı hasta onamı bu olguya katılan hastadan alınmamıştır.

Hakem değerlendirmesi: Dış bağımsız.

Yazar Katkıları: Fikir - Yazar Katkıları: Fikir - S.B.S.; Tasarım - G.A.; Denetleme - Ö.G.; Malzemeler - H.A.; Veri toplanması ve/veya işlemesi - H.A.; Analiz ve/ veya yorum - S.B.S., G.A.; Literatür taraması - Ş.E.Ç.; Yazıyı yazan - S.B.S.; Eleştirel Inceleme - Ö.G.

Çıkar Çatışması: Yazarlar çıkar çatışması bildirmemişlerdir

Finansal Destek: Yazarlar bu çalışma için finansal destek almadıklarını beyan etmişlerdir.

Informed Consent: Written informed consent was not obtained from patient who participated in this case.

Peer-review: Externally peer-reviewed.

Author Contributions: Concept - S.B.S.; Design - G.A.; Supervision - Ö.G.; Mate- rials - H.A.; Data Collection and/or Processing - H.A.; Analysis and/or Interpre- tation - S.B.S., G.A.; Literature Review - S..E.Ç.; Writer - S.B.S; Critical Review - Ö.G.

Conflict of Interest: The authors declared no conflict of interest.

Financial Disclosure: The authors declared that this study has received no financial support.

\section{Kaynaklar}

1. Nzewi O, Slight RD, Zamvar V. Management of Blunt Thoracic Aortic Injury. Eur J Vasc Endovasc Surg 2006; 31: 18-27. [CrossRef] 
2. Leonardou P, Pappas P. Urgent endovascular treatment of iatrogenic subclavian artery rupture: report of three cases. Ulus Travma Acil Cerrahi Derg 2012; 18: 527-30. [CrossRef]

3. Assenza M, Centonze L, Valesini L, Campana G, Corona M, Modini C. Traumatic subclavian arterial rupture: a case report and review of literature. World J Emerg Surg 2012 Jun 18; 7: 18. [CrossRef]

4. Fabian TC, Richardson JD, Croce MA, Smith JS Jr, Rodman G Jr, Kearney PA et al. Prospective study of blunt aortic injury: Multicenter Trial of the American Association for the Surgery of Trauma. J Trauma 1997; 42: 374-80. [CrossRef]

5. Caso V, Paciaroni M, Bogousslavsky J. Environmental factors and cervical artery dissection. Front Neurol Neurosci 2005; 20: 44-53. [CrossRef]

6. Umlas J. Spontaneous rupture of the subclavian artery in the EhlersDanlos syndrome. Hum Pathol 1972; 3: 121-6. [CrossRef]
7. Verbert A, Verbist J, Peeters P, Deferm H, Haenen L. Spontaneous rupture of an aneurysm of the right subclavian artery as a first presentation of Ehlers Danlos syndrome in a 15-year old boy. Acta Chir Belg 2013; 113: 367-72.

8. Slisatkorn W, Subtaweesin T, Laksanabunsong P, Warnnissorn M. Spontaneous rupture of the left subclavian artery in neurofibromatosis. Asian Cardiovasc Thorac Ann 2003; 11: 266-8. [CrossRef]

9. Lai V, Tsang WK, Chan WC, Yeung TW. Diagnostic accuracy of mediastinal width measurement on posteroanterior and anteroposterior chest radiographs in the depiction of acute nontraumatic thoracic aortic dissection. Emerg Radiol 2012; 19: 309-15. [CrossRef]

10. Suzuki T, Mehta RH, Ince H, Nagai R, Sakomura Y, Weber F, et al. Clinical profiles and outcomes of acute type $B$ aortic dissection in the current era: lessons from the International Registry of Aortic Dissection (IRAD). Circulation 2003; 108: II312-7.[CrossRef] 